\title{
Estimation of the Meridional Heat and Mass Transport in the South Atlantic by Using the Joint Atmosphere and Ocean Circulation Model with Data Assimilation and Visualization Facilities
}

\author{
K.P. Belyaev¹,A,B,C, A.A. Kuleshov²,C, N.P. Tuchkova3,B,C \\ A Shirshov Institute of Oceanology, Russian Academy of Sciences \\ B Federal Research Center “Computer Science and Control”, Russian Academy of Sciences \\ C Keldysh Institute of Applied Mathematics, Russian Academy of Sciences \\ ${ }^{1}$ ORCID: 0000-0003-2111-2709 \\ 2 ORCID: oooo-0002-4203-9953, andrew_kuleshov@mail.ru \\ 3 ORCID: 0000-0001-6518-5817
}

\begin{abstract}
The joint ocean-Earth-atmosphere model of the Max Planck Institute for Meteorology with application of original data assimilation methods are used to estimate the meridional heat and mass flows. The CTD-sections of temperature and salinity across the Atlantic Ocean for 1991-1995 obtained in the course of the WOCE (The World Ocean Circulation Experiment) international experiment are used as observation data. The sections contain about 650 stations; each of them provides from 100 to 3000 measurements from the sea surface to the bottom. In our study both the control estimates for the velocities of currents and those with assimilation of the data of these experiments are obtained. Using visualization facilities, we have shown how data assimilation changes the model characteristics, including velocities of currents and temperature fields at different sea levels. The graphs demonstrate the influence of the change in the initial field after data assimilation on the results of the model calculations after 6 and 11 months of integration for both the observed model characteristics and those which are not observed directly. The Generalized Kalman Filter (GKF) method which coincides in a particular case with the classical Ensemble Kalman Filter (EnKF) is used as the data assimilation method. The results of calculations of the heat and mass flows are analyzed and compared with those of control calculations with no data assimilation. The calculations were performed on the supercomputers "Mistral" in DKRZ (Deutsches Klimarechenzentrum, Hamburg, Germany) and "Lomonosov-2" in the Lomonosov Moscow State University.
\end{abstract}

This work was supported by the Russian Science Foundation, project no. 14-11-00434.

Keywords: ocean dynamics, supercomputer modeling, MPI-ESM joint model; GKF data assimilation method, WOCE data.

\section{INTRODUCTION}

One of the important problems in modern oceanology is estimating the heat and mass flows in both particular regions and the ocean as a whole. These estimates are necessary for some practical problems, first of all for calculations of the heat and moisture balance on which the medium- and longterm weather forecasts and climatic sce- narios are based. It is impossible to understand these processes without their pictorial presentation with the help of modern visualization facilities. In addition, such values are important to determine the water, chemical pollution, and biogenic elements' transport in the ocean and understand the fauna cyclic genesis in the ocean. It is very difficult to estimate the sea water characteristics and its enthalpy in the deep 
ocean. Unlike the ocean surface, for which the satellite observations describe relatively reliably the sea surface temperature and ocean level, there are not long series of observations for deep sea layers, except for some relatively small volume of data obtained in large-scale international projects $[1-2]$, as well as the data from the Argo drifters [3], collected during the past decade. As for the near-bottom layers, especially in the South Atlantic and in the south part of the Pacific Ocean, there are only separate uncoordinated observation data obtained in oceanographic expeditions, in particular, in the course of the WOCE (World Ocean Circulation Experiment) [4]. Therefore, the main tool used to obtain such estimates is model calculations. In the past decade, a considerable progress is made in mathematical modeling of the processes in the ocean and joint geophysical processes in the ocean and atmosphere. The state-of-the-art models of circulation have appeared and are being developed; they include not only the ocean and sea dynamics, but also describe the joint ocean/atmosphere/Earth/ice/carbon/solar -radiation exchange processes, i.e., all physical processes that influence directly or indirectly on the medium- and longterm ocean dynamics. Let us note the most significant recent studies concerning the pure ocean circulation [5] and modeling with the use of joint ocean-atmosphere models [6]. In these studies the problems of describing the processes of ocean and ocean-atmosphere dynamics are solved at a high scientific level by using supercomputers and parallel programming methods.

Nevertheless, computer modeling cannot provide in full measure accurate estimates for such important characteristics as the heat and mass transport in the ocean. This is conditioned by the fact that the models applied for the calculations are not completely adequate to the reality, since they are based on different approximations and hypotheses; the approximations and numerical methods for solving the differential equations of the proposed models add errors to calculated parameters. In addition, there is a lack of real data used in the models as the initial and boundary conditions; these data are often not completely reliable, there are gaps in the series of observations, instrumental errors, etc.

It is possible to increase the modeling accuracy in the problems under consideration by using data assimilation methods, i.e., by correcting the results of model calculations with the help of observed data.

In data assimilation, the fields of calculated parameters is corrected so as to make it, on one hand, satisfy the model equations, i.e., the principal conservation laws, and, on the other hand, approximate the observed values with a sufficient accuracy. As a result, this compensates both the incompleteness of the database of observations and the error of the model itself. Even if the assimilation methods do not solve all problems, their application gives better results as compared with the results with no assimilation, which is shown, for example, in [7].

Data assimilation methods are widely used in modern oceanology for both the prompt forecasts [8] and climate modeling [9]. A great contribution to the development of the theory and methods of data assimilation was made by the school of thought under the leadership of G. I. Marchuk, the founder of this research domain in the USSR (Russia), Academician of the Russian Academy of Sciences [10]. The modern versions of these assimilation schemes, named as the $4 \mathrm{D}-\mathrm{VAR}$ method, use the ideas of the theory of inverse problems and conjugated equations proposed by Marchuk still in the 1970s. For example, the $4 \mathrm{D}-\mathrm{VAR}$ version of the assimilation method is described in detail in [11].

Another approach, alternative in many respects to that above, is the so-called dynamic-stochastic assimilation schemes. Their modern version got the name of the ensemble Kalman filter (EnKF) [12]. It should be noted that a great contribution to the development of this theory and its application was made by Soviet (Russian) researchers under the leadership of the Academician A. S. Sarkisyan [13]. As for the recent publications in this domain, we should note [14]. On the whole, this research field is actively and successfully developed in Russia and abroad. There are 
other approaches to data assimilation, different from these two mainstream approaches; we will not consider them, since this study is not devoted to data assimilation itself; we use these methods only for concrete calculations.

In recent years, the hybrid data assimilation methods combining these two approaches have become especially topical. One of such methods used in this study is the generalized Kalman filter (GKF) method developed by the authors. Its detailed description can be found in $[15,16]$. Below, we present a short description of this method, necessary to understand the matter of this paper.

This study is devoted to searching for the model estimates for the heat and mass transport in the South Ocean. This theme is topical and there are a series of studies devoted to it. It has to do with the necessity to understand the genesis of the water flows that appear, in particular, as a result of the Antarctica ice melting process and propagate up to the Mediterranean and describe them quantitatively [17].

The aims of this study are as follows: (a) modeling of the heat and mass transport in the South Atlantic by using the joint MPIESM (Max Planck Institute - Earth System Model) model, developed in the Plank Institute of Meteorology (MPIMET, Germany) with application of the GKF (Generalized Kalman Filter) authors' hybrid data assimilation method; (b) analyzing these results and comparing them with the control results obtained by means of model calculations with no assimilation; (c) quantitative and qualitative estimating the effect of data assimilation on the final result, especially for the World Ocean zones distant from the data assimilation region, in particular, for the Arctic; (d) pictorial presentation of the results of modeling by means of modern visualization facilities.

The databases of the Institute of Oceanology of the Russian Academy of Sciences (the sections from the WOCE A6-A11 program) were used for data assimilation. The observation data were provided by Prof. E.G. Morozov.

The calculations were performed on the supercomputers "Mistral" in DKRZ
(Deutsches Klimarechenzentrum, Hamburg, Germany) and "Lomonosov-2" in the Lomonosov Moscow State University.

The visualization of the numerical experiments was made by using the Panoply Data Viewer (Panoply 4.9.4, released 2018-0830, NASA, developed by Dr. Robert B. Schmunk) to treat the netCDF, HDF, GRIB geophysical data sets.

\section{MATHEMATICAL MOD- EL, DATA ASSIMILA- TION METHOD, AND OBSERVATION DATA}

\subsection{Mathematical model}

The MPI-ESM global joint model [6] was used as the mathematical model. Since this model is necessary only as a tool of investigation and is not an object of analysis; the peculiarities of its structure and detailed description are not presented here; only necessary information on its configuration and the main parameters is provided.

In our study, we used its high-resolution version with a grid pitch of $0.25^{\circ}$ in the latitudinal direction and with approximately the same, however, varying with latitude, resolution in the meridional direction. There were 40 levels in the vertical direction from the sea surface to the bottom. At that, the first $1000 \mathrm{~m}$ had a higher resolution and contained 20 levels. The model comprises a special block for calculating the ice dynamics which is important to describe the Antarctic circulation, in particular, the circumpolar current; however, it was not analyzed in our study. The investigated region in our study was bounded by $75^{\circ}$ south latitude and $55^{\circ}$ north latitude in the Atlantic Ocean and from the Drake Passage $\left(75^{\circ}\right.$ west longitude) to the Cape of Good Hope ( $15^{\circ}$ east longitude).

A principal scheme of the experiment was as follows: first, the model free run was conducted with forcing over 150 years. For the ocean part, the average "historical" values of temperature and salinity from the atlases of observations [18] were used as the initial data. For the atmospheric part, the corresponding values (heat flows, wind 
velocities, etc.) were taken from the NCEP archives [19]. Conventionally, these data were related to 1800 . With these initial conditions, the model was integrated with calculation intervals from one month to one year to accumulate the values of the ensemble statistics. In such a way, the model was prepared to calculate the current values, while the values of restarts (the ocean and atmospheric characteristics) were archived and used to form the arrays for statistical treatment.

\subsection{Data assimilation method}

Data assimilation was carried out by using the GKF method, according to the formulae

$$
\begin{aligned}
& X_{a}=X_{b}+K\left(Y-H X_{b}\right), \\
& K=\sigma^{-1}(\Lambda-C)(H \Lambda)^{T} Q^{-1}, \\
& \sigma=(H \Lambda)^{T} Q^{-1}(H \Lambda)
\end{aligned}
$$

where $X_{a}, X_{b}$ are the model fields (written in the form of a column bit vector in each grid point) after and before correction, i.e., the analysis and background fields, respectively; $Y$ is the vector of observations, in our case, it is the temperature and salinity vector at the point of observation; $K$ is the Kalman gain (the weighting matrix) whose meaning is to render information about the difference between the observed and model values, i.e., the errors of modeling, to the model itself including unobserved model parameters; $Q$ is the model error covariance matrix determined only for the observed parameters (structurally, this is a positively definite symmetrical matrix); $\Lambda$ and $C$ are temporal trends, i.e., the time derivatives of model and observational parameters, respectively, written as column bit vectors at the grid points; $H$ is the matrix of the linear projection operator from the phase space (set of values) of the model onto the phase space of observations, which interpolates the values of the model to the points of observations and exclude from consideration the unobserved model parameters; the upper index $T$ designates the transposition of a vector and/or a matrix.

The GKF method (1)-(3) is described in detail and theoretically substantiated in $[15$,
16]. It is also shown in these papers that this method generalizes the known Kalman algorithm EnKF [12]. The values of the vector $C$ and matrix $Q$ are considered to be known and are determined, in particular, by the methods described in [15]. The advantages of this algorithm are as follows: it considers not only the difference between the model and observations, but also the temporal trend (the time derivative) in both the model and observation data. At that, this method does not require a preliminary filtration of the model bias, since the consideration of the linear trend as the filter basis eliminates automatically the model bias.

\subsection{Observed data}

In this study, we have assimilated 5 sections of the temperature and salinity profiles from the sea surface $(0-6 \mathrm{~m})$ to the bottom (to $5720 \mathrm{~m}$ ) performed by boats of different countries in the course of the WOCE international experiment at about 650 stations. The charts of the sections are shown in Fig. 1 (provided by Prof. E. G. Morozov).

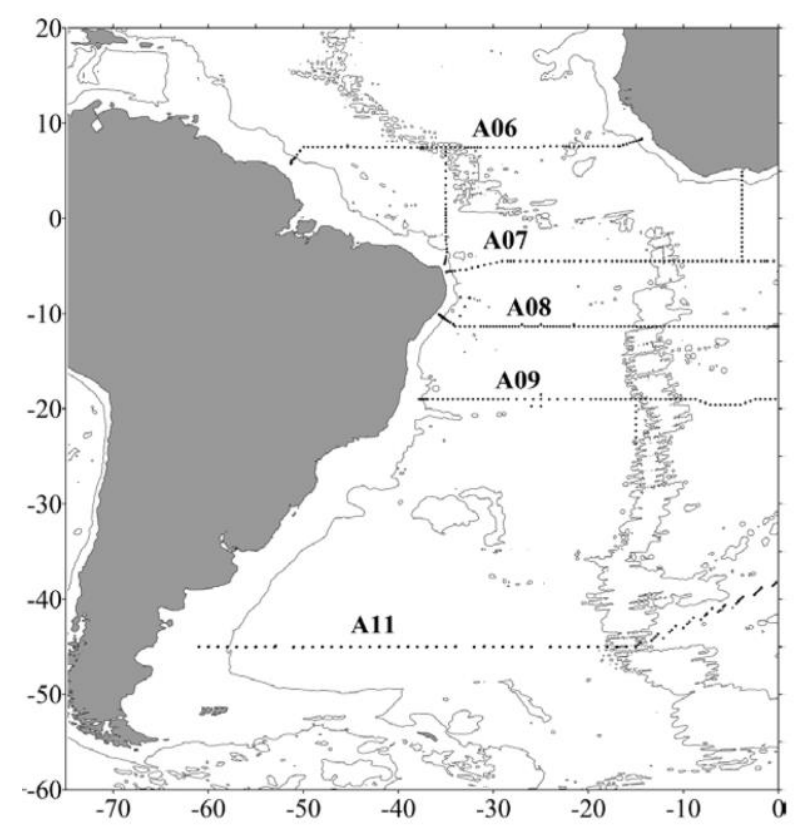

Fig. 1. Scheme of the stations' location

The observed data are the temperature and salinity profiles with a pressure interval of 2 dbar. These values were recalculated to the standard depth levels of the model and subjected to a quality control. In particular, we verified the stratification condition 
$\rho_{k+1}>\rho_{k}, k=1,2, \ldots, 39$, where $\rho_{k}$ is the density at the $k$-th depth level. If the stratification condition was violated, then, at the depth levels where this violation was observed, the temperature and salinity data were transposed and the procedure was repeated until the stratification condition was strictly satisfied. In addition, the temperature in situ in the observations was converted to the potential temperature, according to [20]. It should be noted that the difference between the potential and in situ temperatures proved to be about $0.8^{\circ} \mathrm{C}$ at the depths that exceeded $3000 \mathrm{~m}$. This conversion significantly reduced the difference between the model and observed temperatures, as compared with the initial values.

\subsection{Model experiments}

As was noted above, the model free run was conducted with atmosphere forcing over 150 years, beginning from the conventional 1800 with zero initial velocities. In the process of integrating, the calculation data were recorded and archived for each month. In such a way, the ensemble of values was formed. These data were used to calculate by the Monte-Carlo method the vector $C$ as an ensemble average of the difference between two parameters in two successive model calculations divided by the time pitch and the model error covariance matrix $Q$.

It was established in previous investigations [14] that it is sufficient for data assimilation to have an ensemble of about 50 values for each ocean characteristic (temperature, salinity, horizontal and vertical velocities, ocean level, etc.). Therefore, the annual averages for the conventional 1900-1950 were used as the ensemble's components. Further, the calculations were performed from the conventional 1950 to 1993 without and with data assimilation, according to formulae (1) - (2) at one instant of time, namely, the conventional 1993, however, the real measurements were carried out during a few months. The parameters obtained in the calculation were compared with the results of calcula- tion without data assimilation (the control calculation). 


\section{RESULTS OF EXPERIMENTS AND THEIR ANALYSIS}

Figure 2 shows the temperature fields at a depth level of $150 \mathrm{~m}$ before their assimilation (control, Fig. 2a), after data assimilation (analysis, Fig. 2b), and their difference (analysis minus control, Fig. 2c). The level of $150 \mathrm{~m}$ was chosen, since the structure of currents typical of the South Atlantic Ocean is well seen at it.

\section{Поле модельной потенциальной температуры на уровне 150 м}

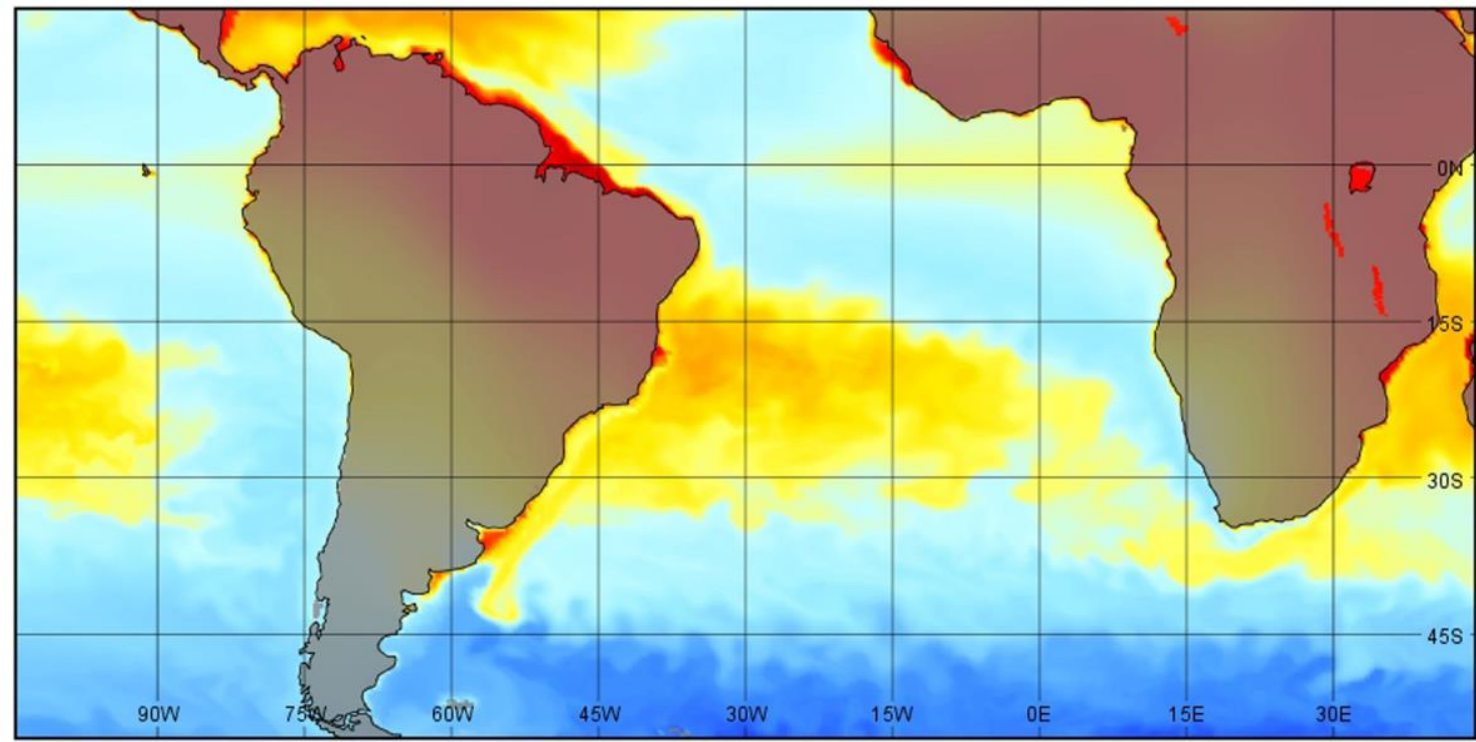

Sea water potential temperature $(\mathrm{C})$

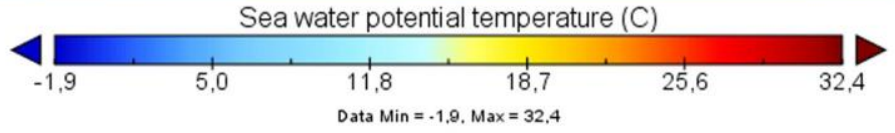

(a)

Поле потенциальной температуры после усвоения на уровне 150 м

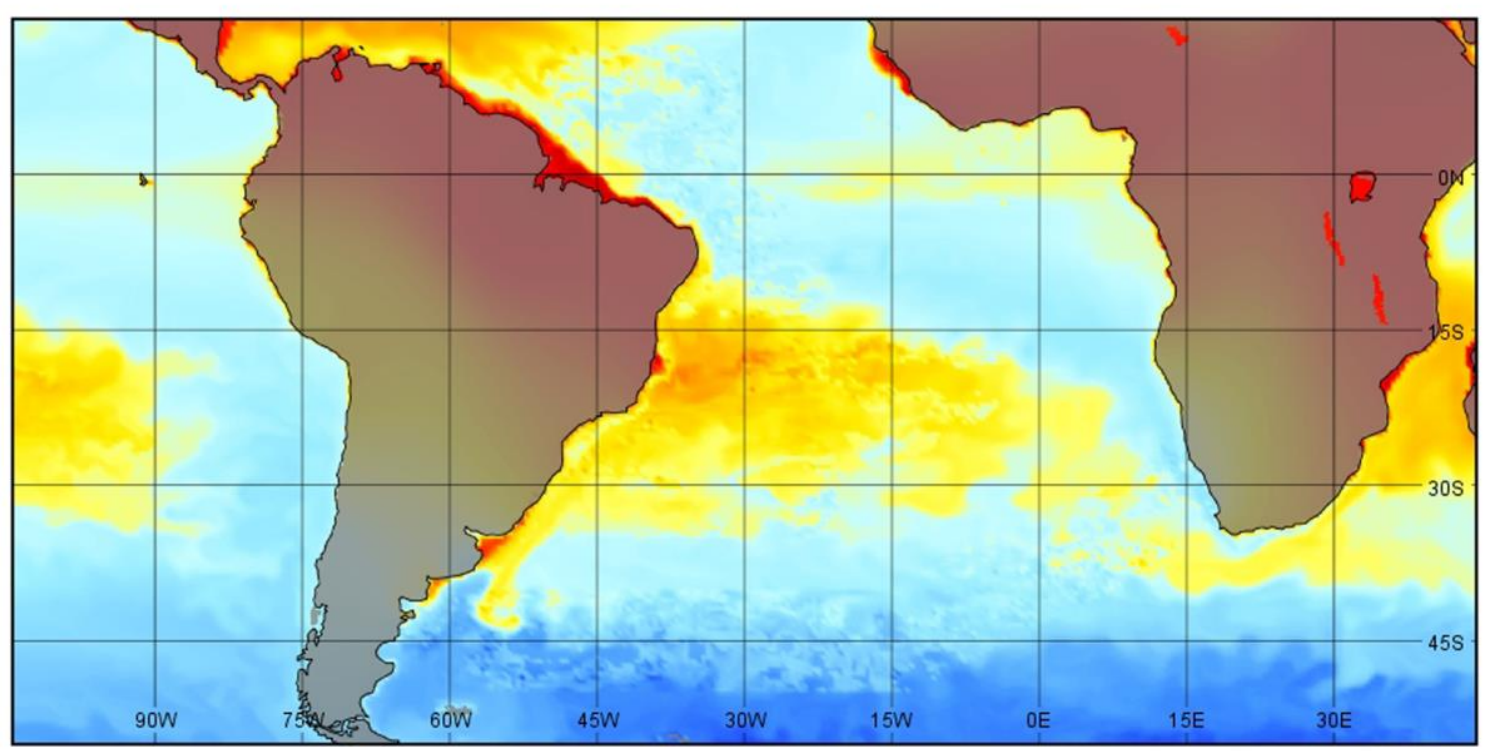

Sea water potential temperature (C)

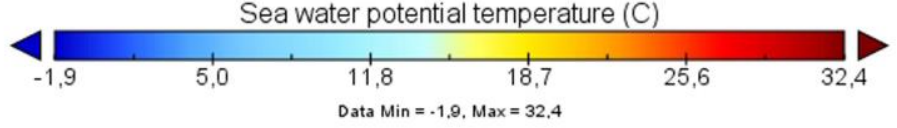

(b) 

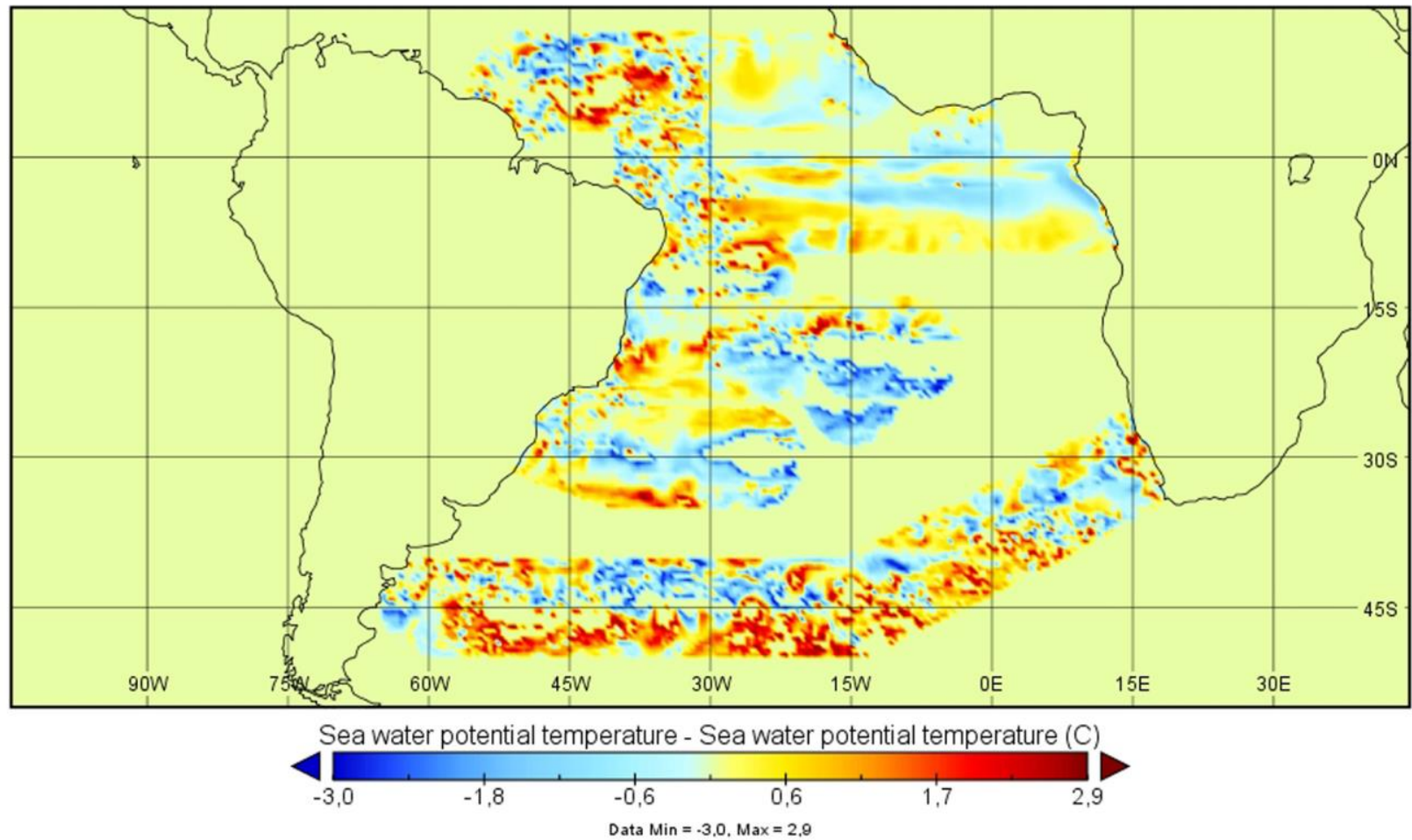

(c)

Fig. 2. Temperature fields at a depth level of $150 \mathrm{~m}$ : (a) control calculation; (b) analysis (calculation with data assimilation); (c) difference between the analysis and control calculations

It is seen in these figures that the control field is quite smooth, nearly without synoptic structures, without well-marked changes in both latitudinal and meridional directions. On the contrary, the analysis field is more dynamic; on the whole, it is warmer than the pure model field, especially in the equatorial region with a marked synoptic variability in the south part, near the coasts of the Latin America in the Brazil-Malvinas confluence zone and in the Gulf of Guinea, in Africa. These two differences are seen in Fig. 2b, which represents the difference between the fields. The zones of data assimilation are well-marked; however, the structure of this difference is strongly anisotropic and inhomogeneous. The value of the difference has the maximum amplitude (both with plus and minus signs) about $2^{\circ} \mathrm{C}$ and considerably varies with latitude. In the equatorial region, the model significantly underestimates the real data, while in the region of the Brazil current the real temperature is considerably lower than the model value.

Figure 3 shows the temperature fields at a depth level of $3770 \mathrm{~m}$. For illustration, this depth level is chosen because the Antarctic deep water (AADW), which is of great interest for climatic research, manifests itself at this level. The fields at this depth level vary insignificantly; however, there are some small differences. The conclusion that the model somewhat underestimates the deep water temperature remains; the field after the correction (data assimilation) is approximately by $0.5^{\circ} \mathrm{C}$ warmer than the control field; however, in some regions, the difference between them reaches $1^{\circ} \mathrm{C}$. This difference is most remarked in the Brazil-Malvinas confluence zone and in the Drake Passage region. This underestimate significantly influences on the correction of the velocity and especially on the correction of the heat flows, since the latter is a multiplier of two variables: the velocity and temperature. температуры. 
Модельное поле потенциальной потенциальной тепературы на уровне 3770 м

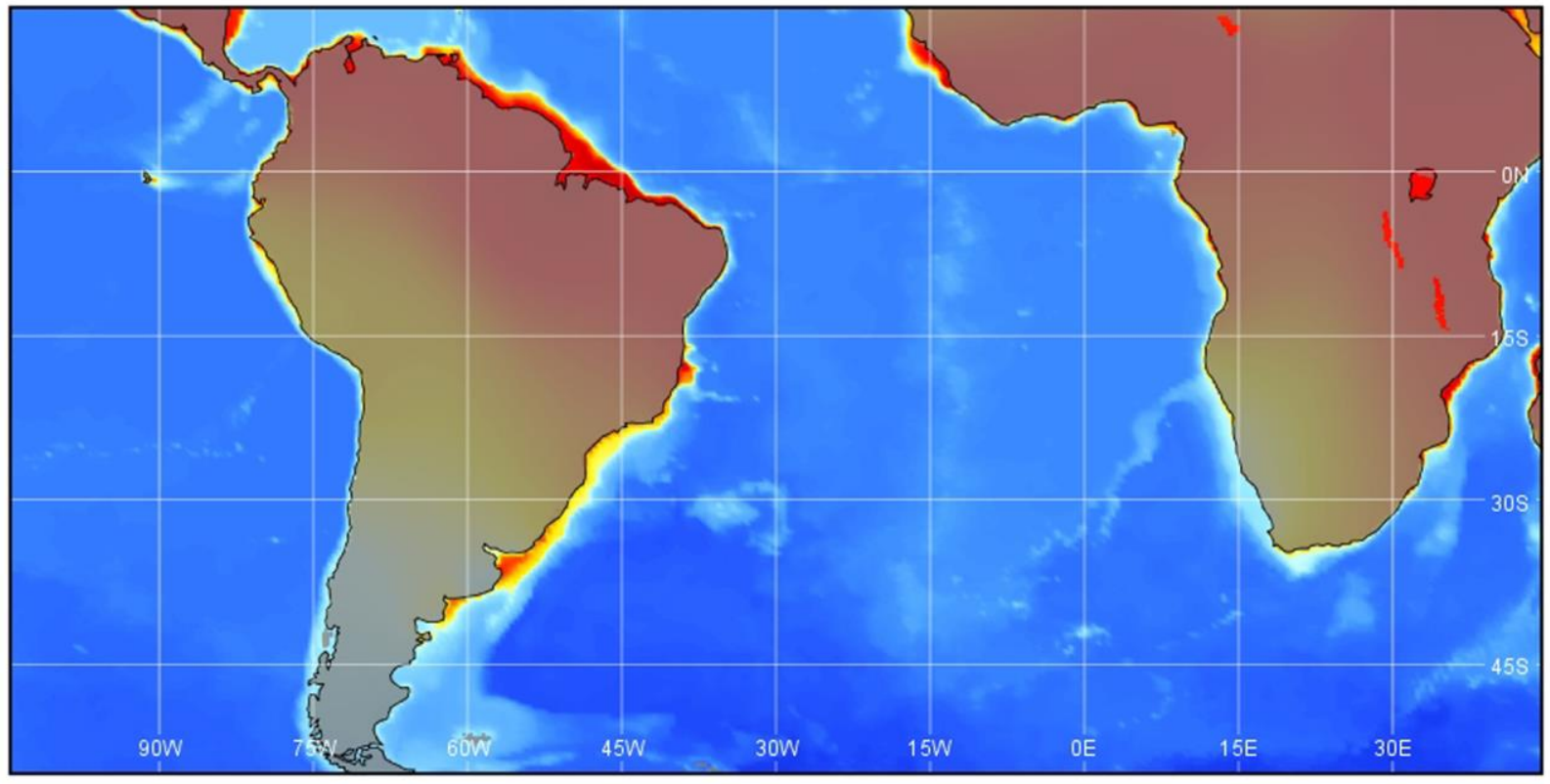

Sea water potential temperature (C)

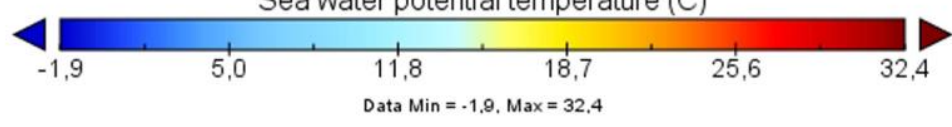

(a)

Поле топенциальной температуры после усвоения на уровне 3770 м

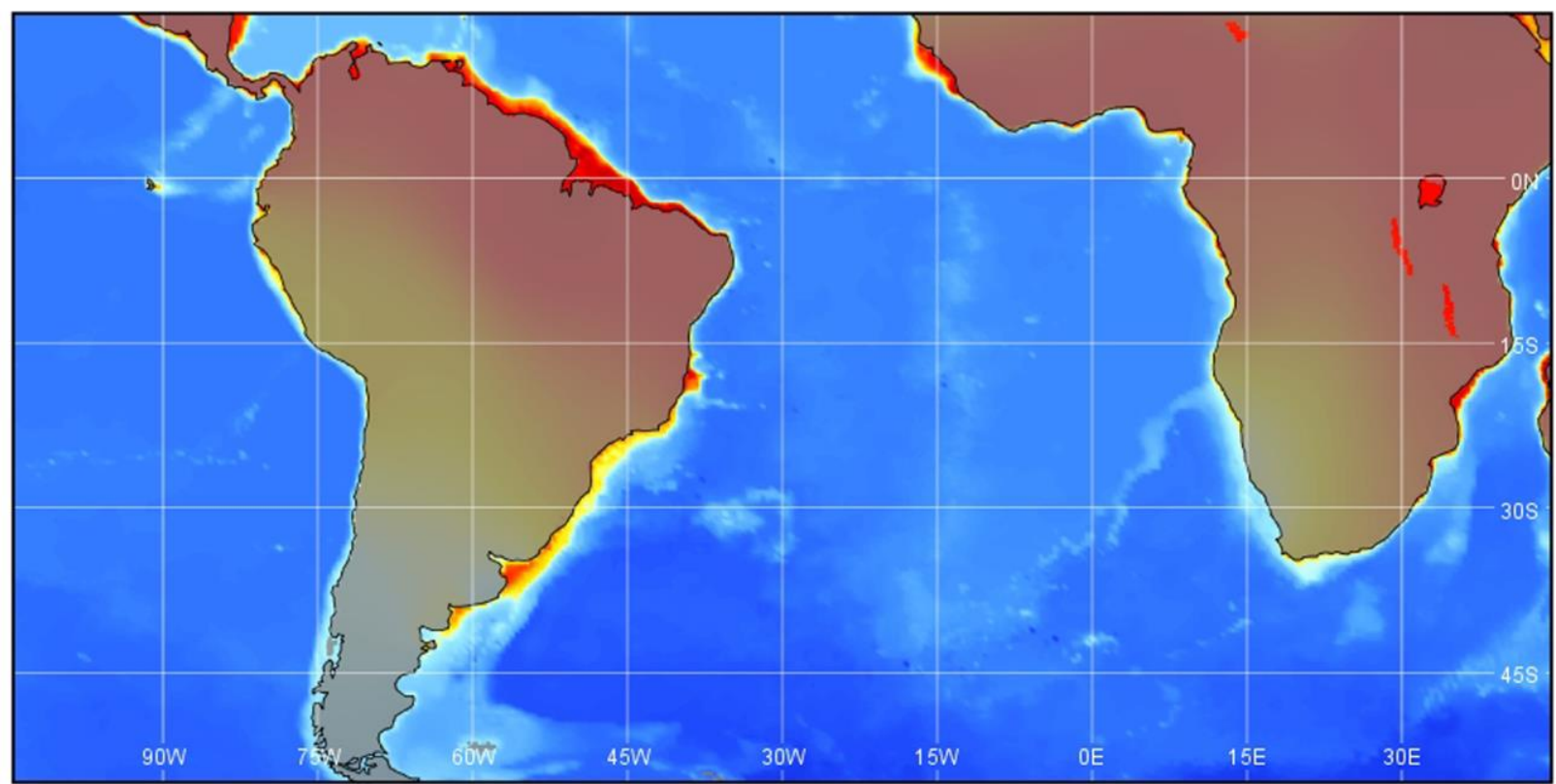

Sea water potential temperature $(C)$

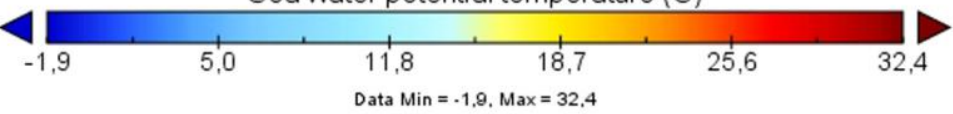

(b) 




Sea water potential temperature - Sea water potential temperature $(\mathrm{C})$

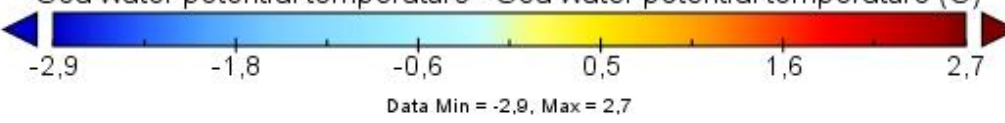

(c)

Fig. 3. Potential temperature at a depth level of $3770 \mathrm{~m}$ : (a) control calculation; (b) analysis, (c) difference between the fields of analysis and control calculations

Let us analyze the meridional component of the velocity of currents. Figure 4 shows the meridional component of the velocity of current at a depth level of $150 \mathrm{~m}$ before and after data assimilation and the difference between them; Fig. 5, the same parameters at a depth of 3770 m.

Модельное значение меридиональной компоненты скорости течений на уровне 150 м

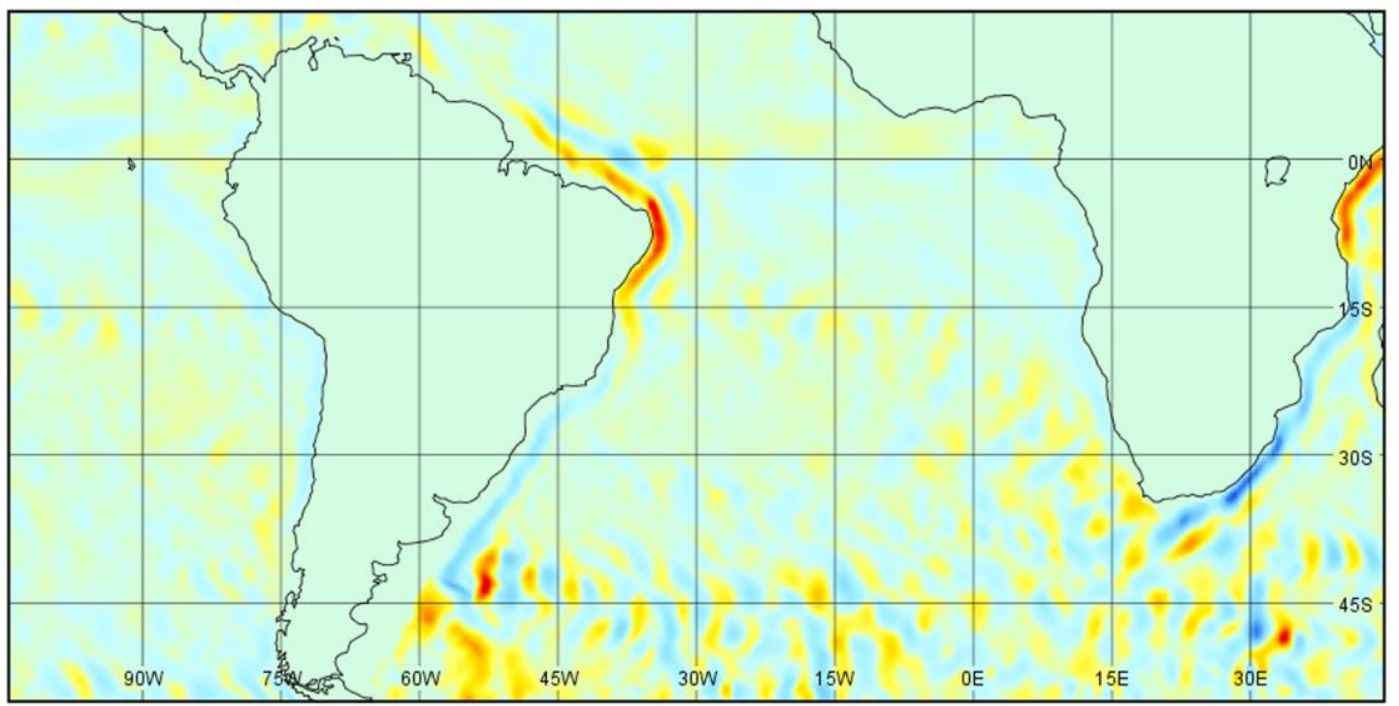

Sea water y velocity ( $\mathrm{m} \mathrm{s}-1)$

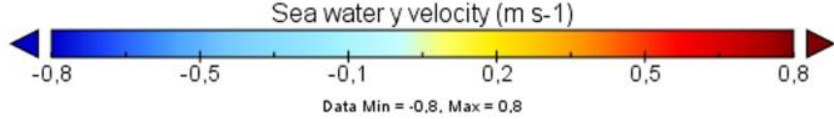

(a) 




Sea water y velocity (m s-1)

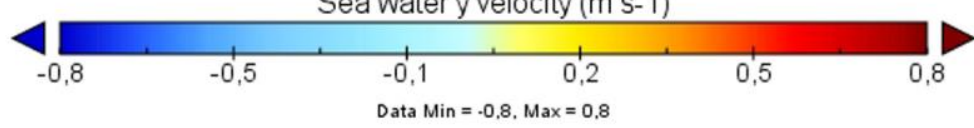

(b)

Разница меридиональной компоненты скорости после и до усвоения на уровне 150 м

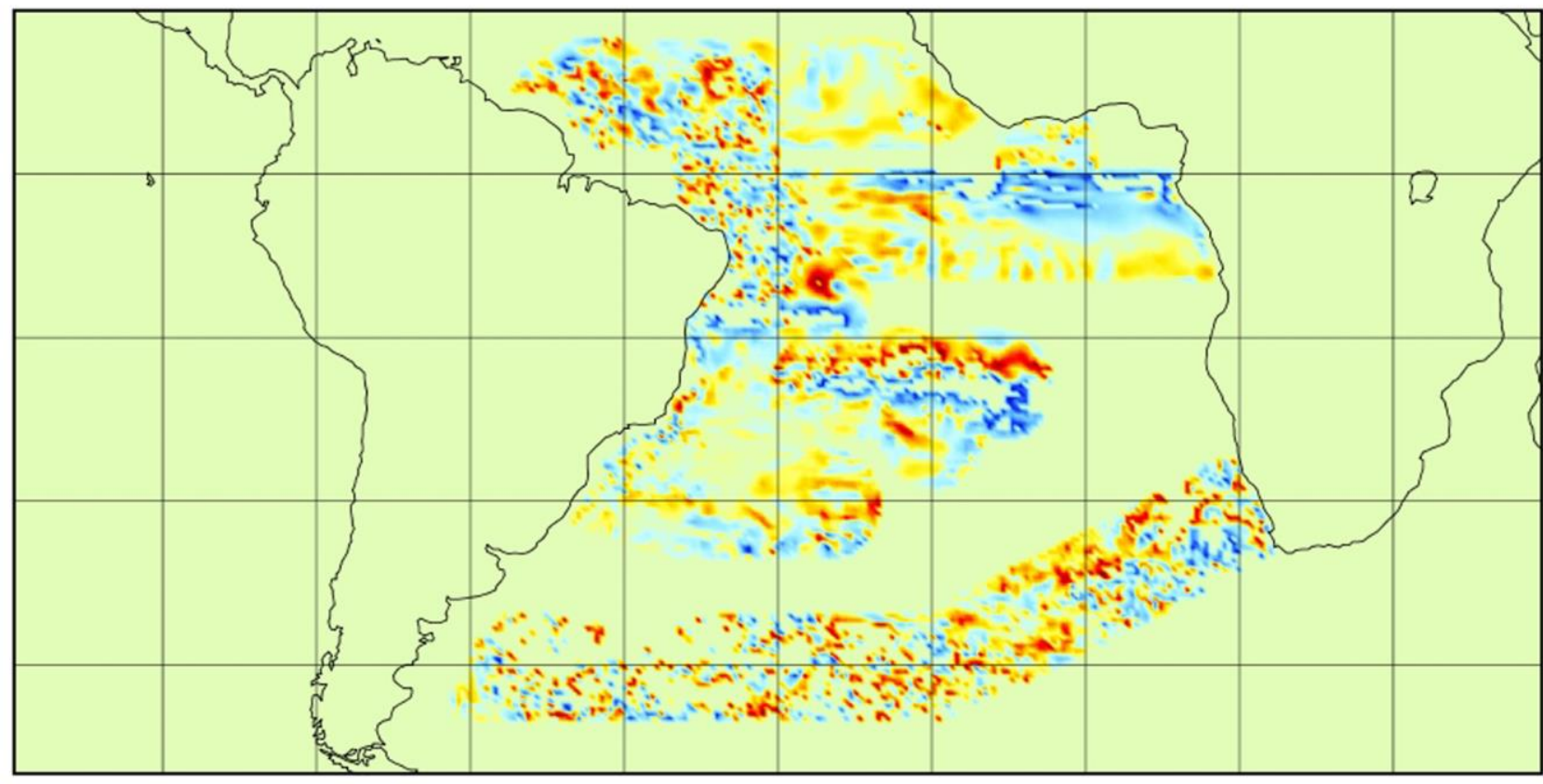

Sea water y velocity - Sea water y velocity ( $\mathrm{m} \mathrm{s}-1$ )

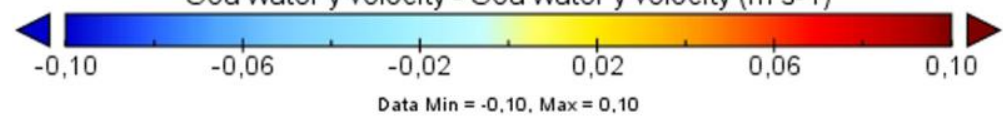

(c)

Fig. 4. Meridional component of the velocity of current at a depth level of $150 \mathrm{~m}$ : (a) control calculation; (b) analysis; (c) difference between the analysis and control fields 
Like in the case of the temperature field, one can notice that the velocity field becomes more chaotic, with a well-marked synoptic variability. At that, the structure of the Brazil and Malvinas currents along the coasts of Brazil and Argentina is well seen. In Fig. 4b, a synoptic structure of the equatorial counter-current flow manifests itself, while it is almost unnoticeable in Fig. 4a, since it has a pronounced zonal direction rather than the meridional direction. The amplitude corrections are not large; they do not exceed $0.05 \mathrm{~m} / \mathrm{s}$. However, the model velocity does not have any pronounced tendency to increasing or decreasing. In the regions of the Brazil-Malvinas confluence, one can notice the maximum of amplitudes of both positive and negative corrections. In addition, one can notice the "tongues" of these quantities in the zones of the Equatorial and (North (South) Equatorial currents. On the whole, the water dynamics in both cases with and without data assimilation corresponds to the universally recognized pattern of currents known from other studies [5].

At a depth of $3770 \mathrm{~m}$, the charts of fields do not have a pronounced structure. Figure $5 \mathrm{a}$ shows the meridional component of velocity for the control field; Fig. 5b, for the corrected field; Fig. 5c, the corrections for the deep-water current in the meridional direction. It should be noted that the amplitudes of these corrections are not lower than those at a depth of $150 \mathrm{~m}$ and even exceed them in some cases. In Fig. $5 \mathrm{c}$, a track of about $0.06 \mathrm{~m} / \mathrm{s}$ is noticeable in the west-east direction in the region of the $45^{\circ}$ south latitude, as well as a small negative difference between the meridional components of velocity after and before data assimilation for the currents along the America continent in the central Atlantic.

Модельное значение меридиональной компоненты скорости течений на уровне 3770 м

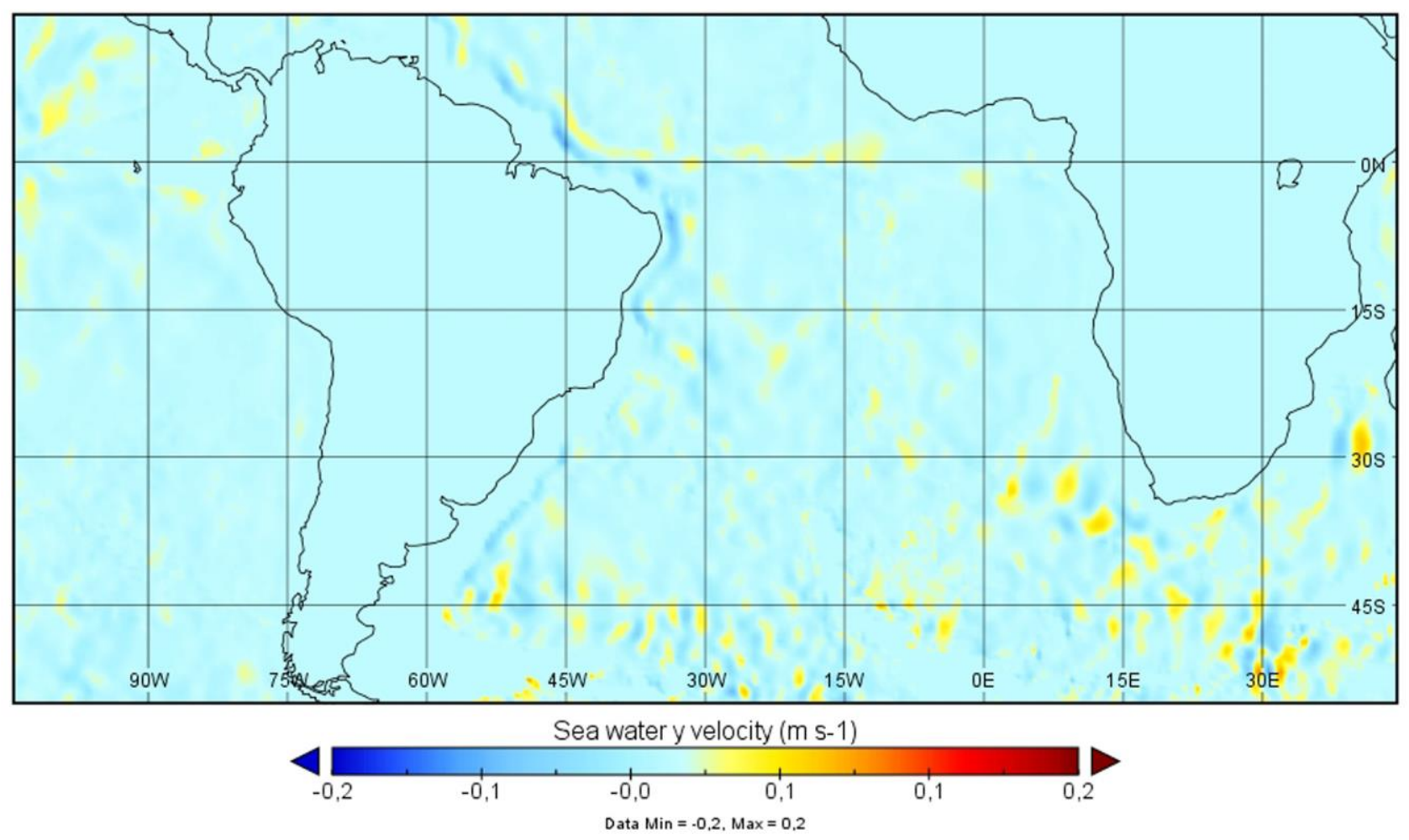

(a) 


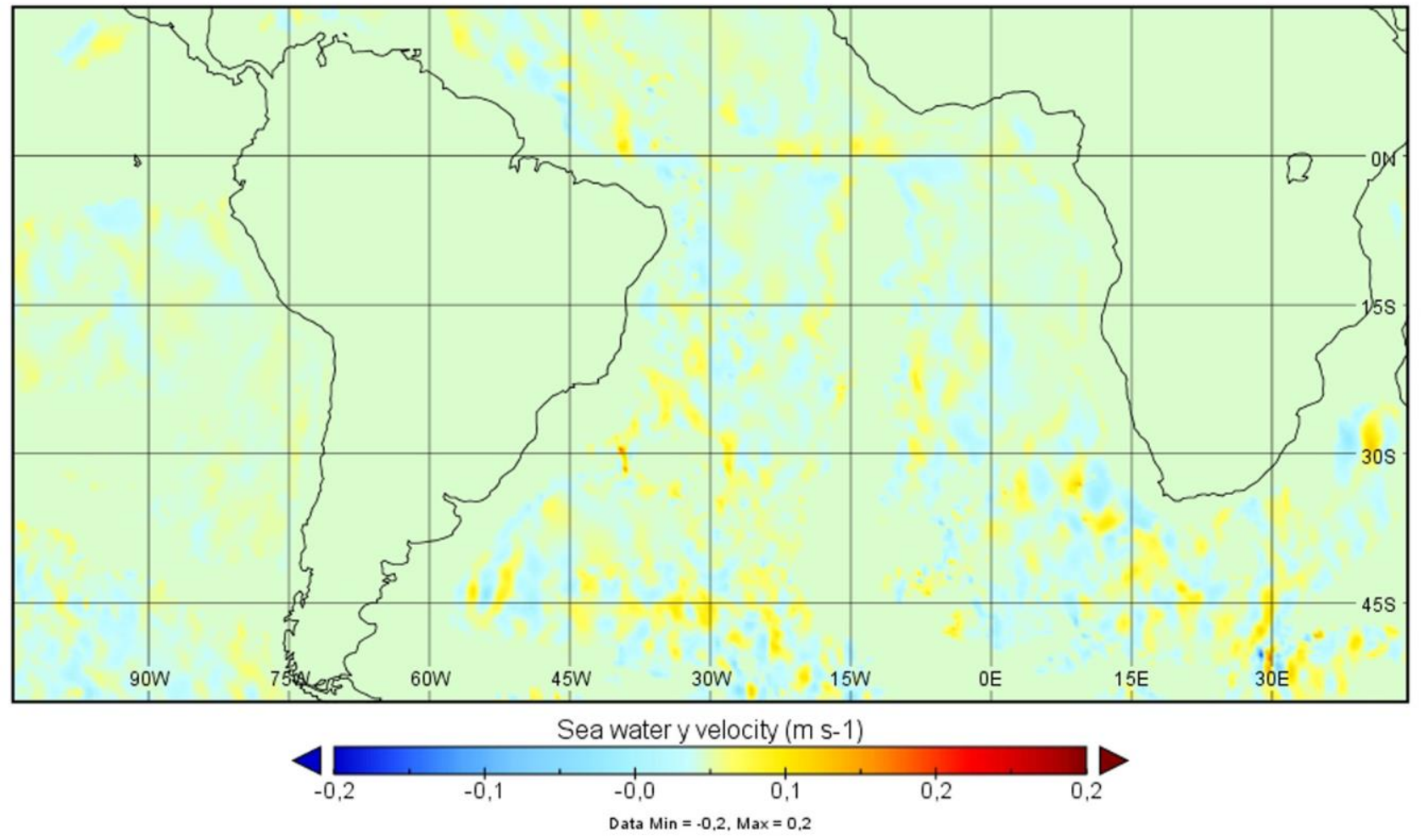

(b)

Разница меридиональной компоненты скорости после и до усвоения на уровне 3770 м
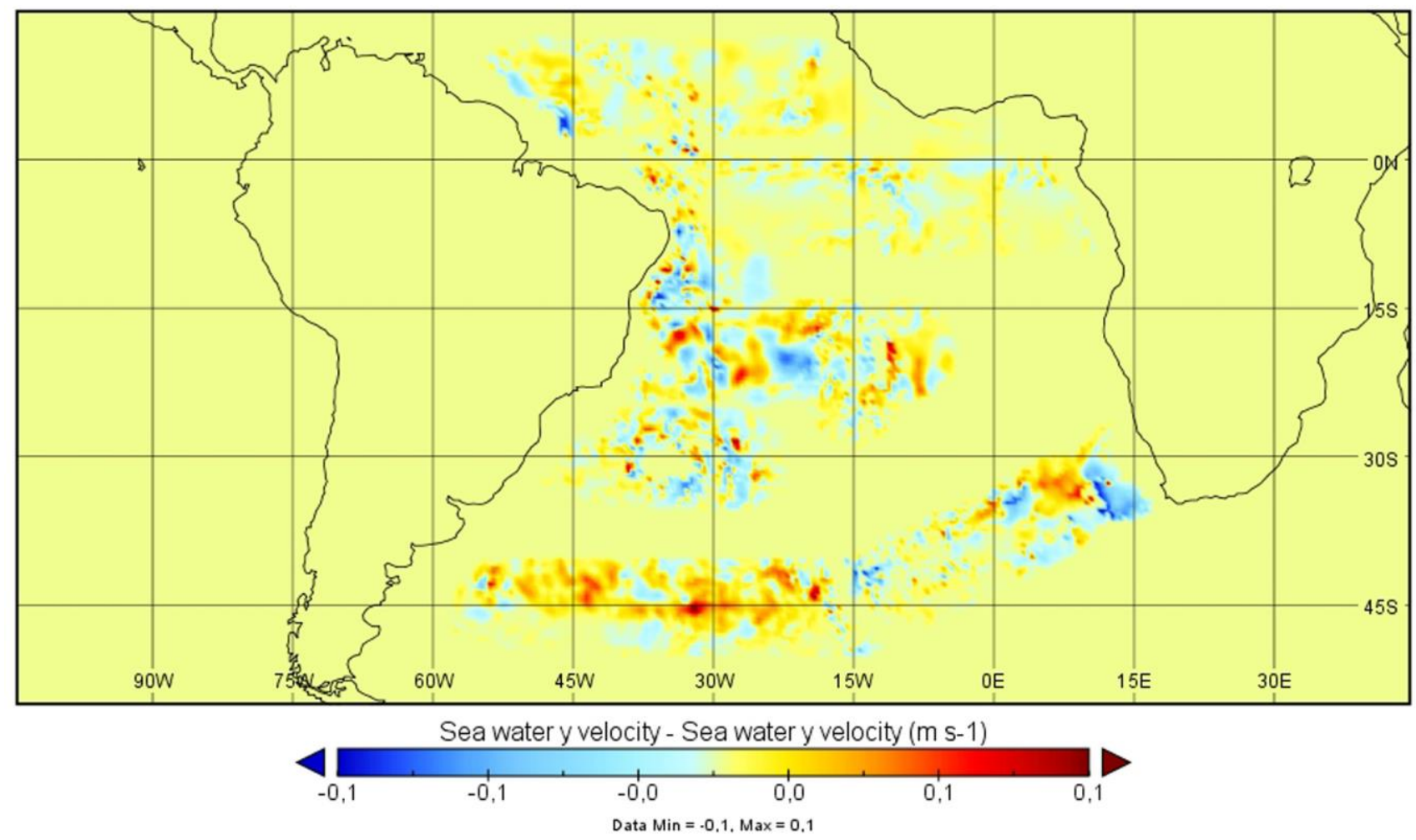

(c)

Fig. 5. Structure of the meridional component of the velocity of currents at a depth level of $3770 \mathrm{~m}$ : (a) control calculation; (b) analysis; (c) difference between the analysis and control fields 
Figure 6 shows the meridional mass transport in the South Atlantic. We have calculated both the total meridional water mass transport and the transport of the AADW mass, which was separated according to the criterion PT $<2{ }^{\circ} \mathrm{C}$ [23], where PT designates the water potential temperature. Figure 6a shows the total water transport in the meridional direction; Fig. 6b, only the AADW transport. The mass transport was calculated according to the formula

$$
M=\oiint_{s} v d \sigma
$$

where $M$ is the total mass transport at a fixed latitude; $v$ is the meridional component of the velocity of flow in a current point at the fixed latitude and depth level. The integration is made over each latitude and vertical, from the surface to the bottom. In the case of the AADW transport calculation, the corresponding integral is taken only over such a region (not fixed beforehand) where the potential temperature is lower than $2^{\circ} \mathrm{C}$. The unit of flow is a Sverdrup $\left(1 \mathrm{~Sv}=10^{6} \mathrm{M}^{3} / \mathrm{c}\right)$.

Let us make the following remark. The detailed analysis of the AADW transport requires a special consideration, as well as its comparison with the analogous calculations performed earlier by using other methods and models, for example, in [21]. In this study, only some estimates are made. This problem will be studied more in detail in another paper.

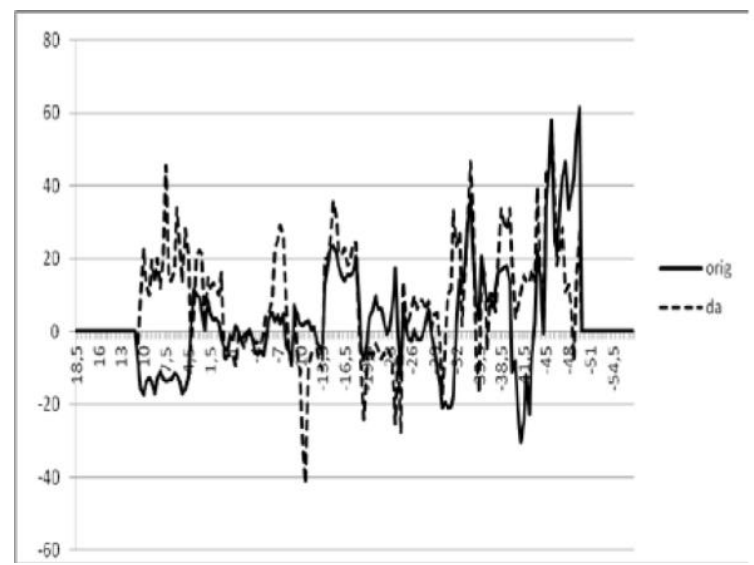

(a)



(b)

Fig. 6. Mass transport in the South Atlantic: (a) integral; (b) only for the AADW

In Fig. 6a, the solid line indicates the mass transport for the model calculation (control); the dotted line, the results of calculation of the mass transport by using the corrected (assimilated) velocities. It is seen that these curves are significantly different. At that, the values of the corrected mass transport are considerably, sometimes by two times, larger than those of the control mass transport; even the direction of the mass transport can be different. In fact, there is nothing astonishing in this: as is seen in the above-presented figures, in the upper levels, there is a well-remarked synoptic component of the meridional velocity that can make a significant contribution to the transport, which is different from the control one. Even a small discrepancy between the control and assimilated velocities after integrating over a considerable area can give and really gives large discrepancies, both quantitative and qualitative, between the control and assimilated values of the mass transport $M$. However, the maximum and minimum values of the control and corrected mass transport are nearly identical and are equal to $+60 \mathrm{~Sv}$ and $-40 \mathrm{~Sv}$, respectively; at that, the regions of their maxima and minima do not coincide. We can come to conclusion that the total (integral) and average (normalized by the area) control and corrected mass transports are close in their values, however, being locally different.

Figure 6b shows the curves of the AADW transport. Like in Fig. 6a, the control flow is shown by the solid line; the corrected flow, by the dotted line. One can notice that the AADW transport occurs strictly in the north direction up to $46^{\circ}$ south latitude and in the south direction below this boundary. At that, the flows in the south direction for the control calculation 
and for that with assimilation nearly coincide with each other, which can be explained by the absence of the observed data for the regions located southward of $46^{\circ}$ south latitude, while in the northern direction, they are noticeably different both quantitatively and qualitatively. The maximum value of the control flow is approximately $8 \mathrm{~Sv}$, while with data assimilation, this value increases twice, up to $15 \mathrm{~Sv}$. The maxima of flows are shifted in their latitude: for the control flow, it occurs at the $40^{\circ}$ south latitude, while for the assimilated flow, it occurs at the $42^{\circ}$ south latitude. At that, as is seen from Fig. 6, there is no considerable difference between their velocities; those are the flows that differ from each other.

In addition, we have calculated the meridional heat flows: the integral flow and the flow only for the AADW. The calculation of the heat flows was performed according to the formula

$$
Q=S^{-1} \iint_{s} c_{p} \rho v T d \sigma
$$

where $Q$ is the total heat flow for each latitude; $S,{ }^{c}, \rho, v, T$ are the sectional area, specific heat capacity with a value of $4220 \mathrm{~J} /(\mathrm{kg} \cdot \mathrm{grad})$ [20], density with a value of $10^{3}\left(\mathrm{~kg} / \mathrm{m}^{3}\right)$, meridional component of velocity $(\mathrm{m} / \mathrm{s})$, and temperature $\left({ }^{\circ} \mathrm{C}\right)$. The integral is taken over the latitude and over the entire vertical, from the sea surface to the bottom. Correspondingly, for the AADW, the region is chosen where $\mathrm{T}<2^{\circ} \mathrm{C}$. The flow is measured in $\mathrm{W} / \mathrm{m}^{2}$.

Figure 7a shows the integral heat flow; Fig. 7b, the heat flow in the AADW.

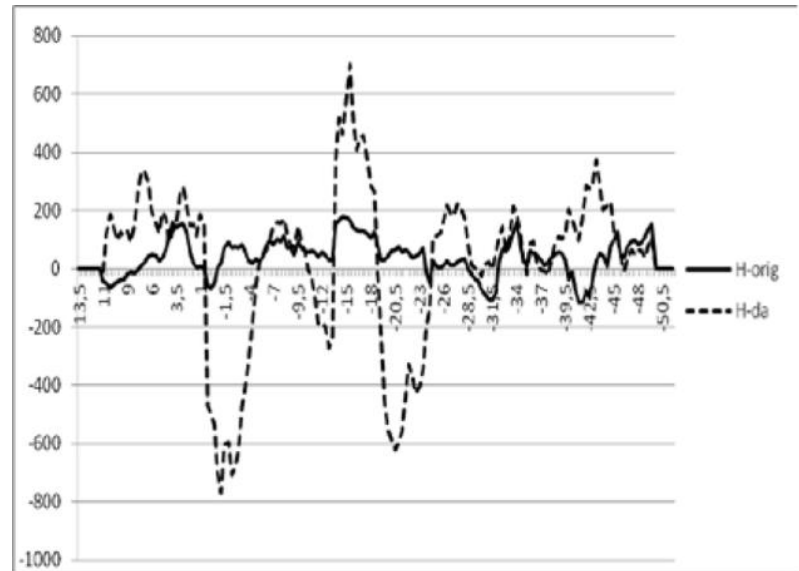

(a)

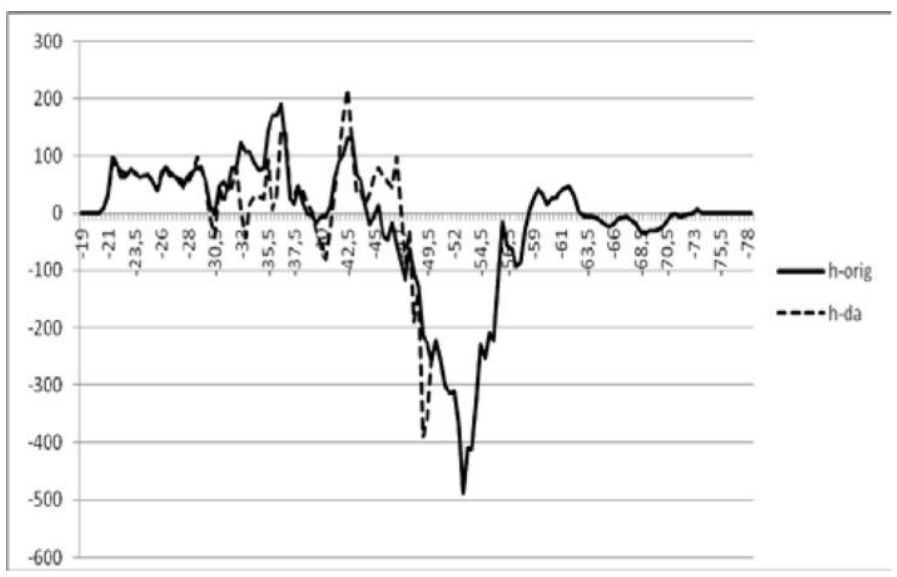

(b)

Fig. 7. Meridional heat flow in the South Atlantic: (a) integral; (b) for the AADW

We can notice that in the integral heat flow, the difference between the corrected and pure model curves can be both positive and negative; at that, their average values (the areas under the curves) are close to each other. It means that the flows considerably differ locally but not summarily. It is reasonable that the assimilated values of the meridional heat flow are considerably larger in their moduli than the control values; sometimes the difference between them can reach one order of magnitude, since the assimilated values of heat flow are the product of two corrected quantities - the velocity and temperature and, thus, as a result, we have a multiplicative effect. However, the general integral heat balance is conserved, which proves indirectly the correctness of our calculations. Figure $7 \mathrm{~b}$ shows that the heat transport for the AADW corresponds to the mass transport (Fig. 6b), it also has well-marked flows to the north from the $46^{\circ}$ south latitude and to the south from this boundary. However, there is a positive value of the heat transport in the region of the $62^{\circ}$ south latitude. It can be explained by the presence of negative values of temperature at a depth of about $4500 \mathrm{~m}$ and deeper. Even in the case of the general mass flow passing in the south direction, the heat transport occurs in the north direction. 


\section{GLOBAL INFLUENCE OF THE CHANGES IN THE FIELDS IN THE SOUTH ATLANTIC ON OTHER REGIONS OF THE WORLD OCEAN}

Since the experiments are carried out with the joint ocean-atmosphere model, the local changes in particular regions of the ocean will cause a global effect through the changes in the fields in both the atmosphere and ocean. At that, in the case of the changes in the initial values of the model parameters due to data assimilation, we can assert that the fields of parameters in the subsequent integration will be balanced and the conservation laws will hold true. This is a distinct point of our study in comparison with the model sensitivity experiments [22], in which the initial conditions are given quite arbitrary and the model behavior is investigated with no consideration of the balance of all model parameters.

In our study, the initial control state without data assimilation and another case with the initial state obtained as a result of data assimilation by the GKF method were considered. The model was integrated forward for 11 months starting from these two initial states independently of each other. Figure 8a shows the difference between the assimilated and control sea surface temperature fields after 11 months of integration; Fig. 8b, the difference between the assimilated and control meridional velocity fields.

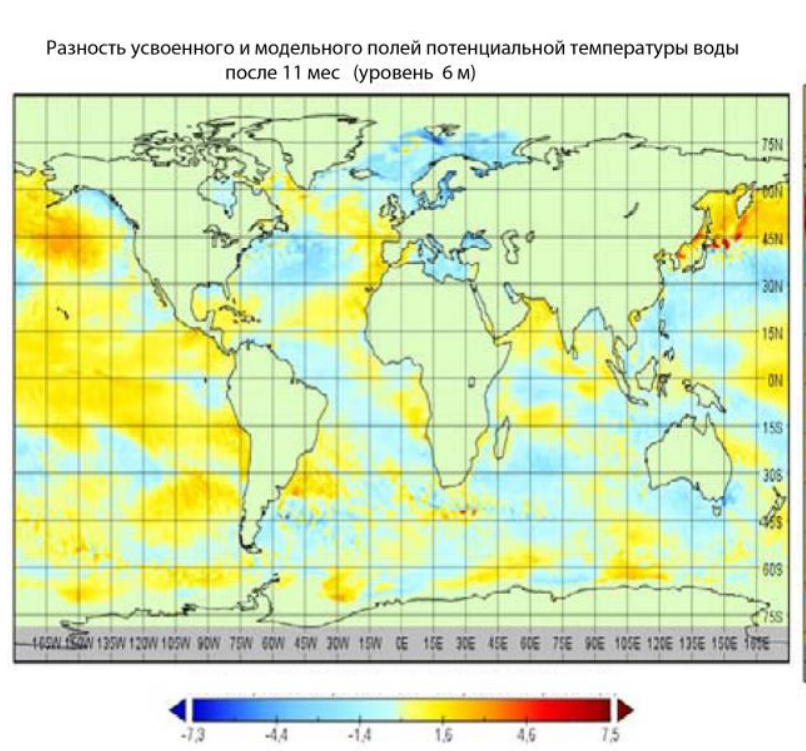

(a)

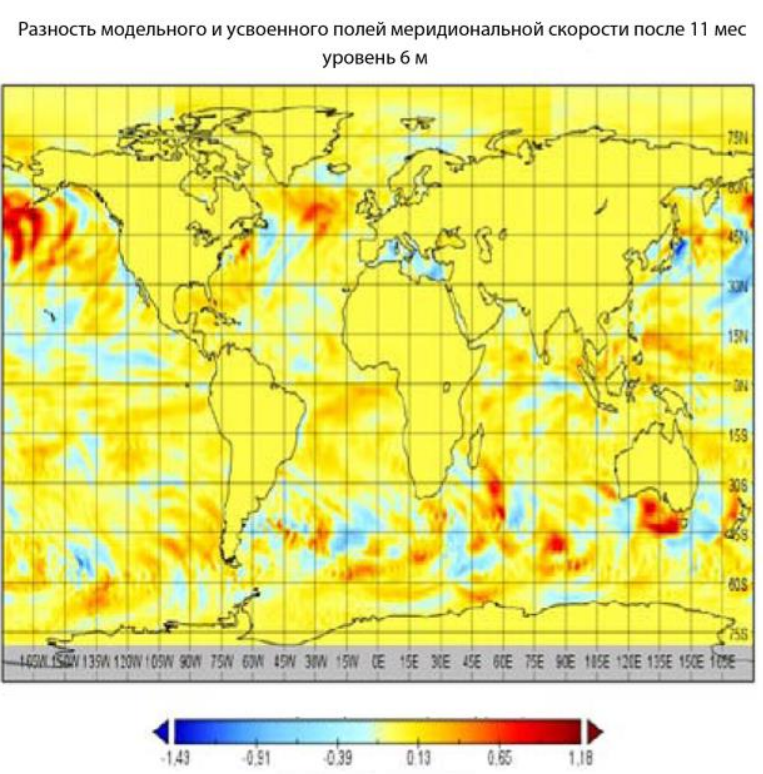

(b)

Fig. 8. Difference between the fields of parameters after 11 months of integration from the initial control filed without data assimilation and from the initial field with data assimilation: (a) difference between the surface temperature fields; (b) difference between the meridional velocity fields

It is seen that the changes have a global character and they are relatively small, except for some particular regions. On the whole, the difference between the sea surface temperature fields does not exceed $1^{\circ} \mathrm{C}$, except for a region in the Kuroshio Current zone in the Pacific Ocean and to the south from the Gulf of Alaska, where the changes are more considerable, which is related above all to the stronger interactions between the ocean and atmosphere in these regions (so-called the energy-active zones). One can see the intensification of the meridional currents in these regions; the differences between the assimilated and control meridional velocity fields are larger than $1 \mathrm{~m} / \mathrm{s}$. In addition, it is seen from Fig. $8 \mathrm{~b}$ that as a result of data assimilation, the Gulf Stream (the North Atlantic Current) is intensified to the south from the Greenland, which is well confirmed by independent observations. In other regions, 
the changes in the meridional velocity are relatively small and are most likely caused by the changes in the atmospheric circulation due to the initial field correction.

The changes in the initial filed have effects on such a characteristic as the sea ice area fraction in the Arctic. Figure 9 shows the difference between the analysis and control ice area fraction fields. It is seen that this zone as a whole is reduced, except for a relatively narrow region near the Spitsbergen and the adjacent region. This also corresponds to the observed data and the results obtained in earlier investigations [23].

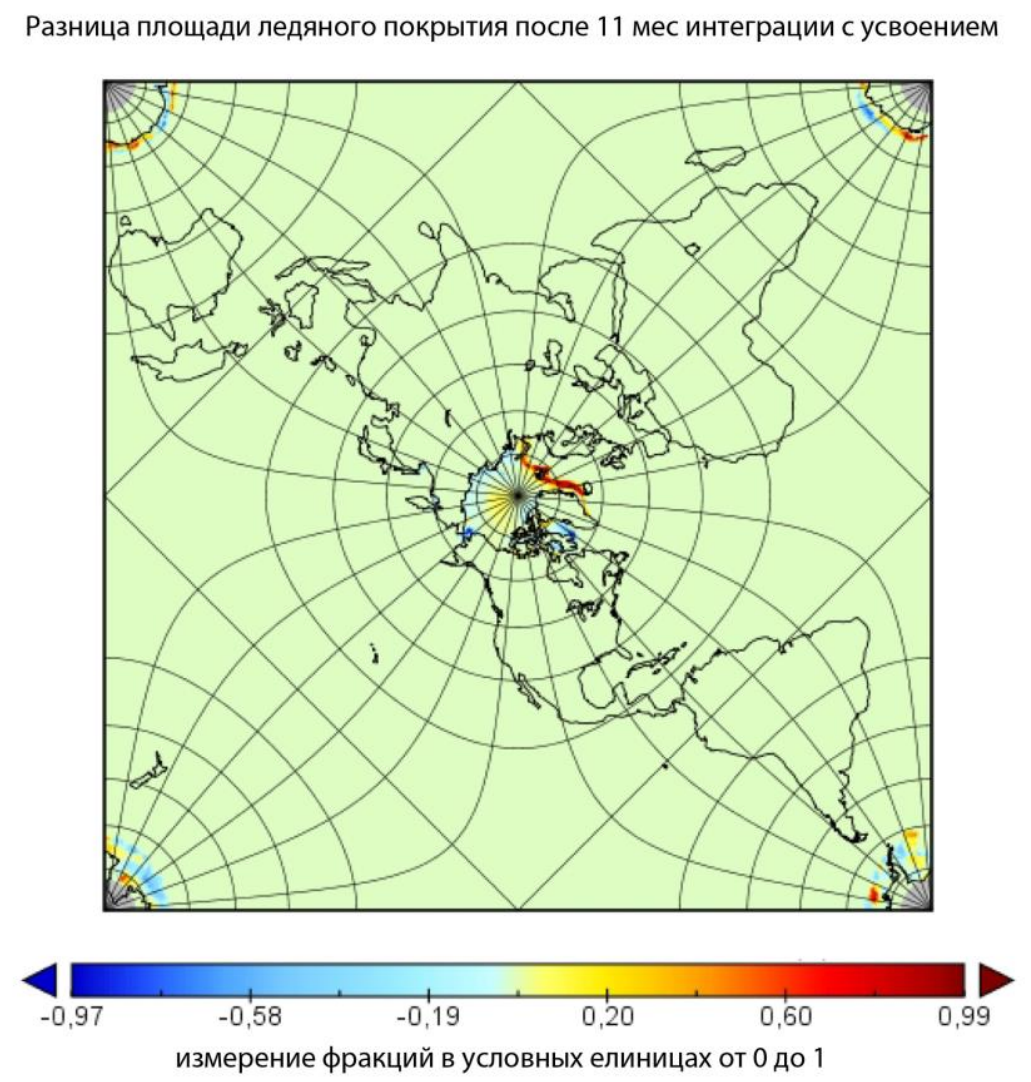

Fig. 9. Difference between the analysis and control sea ice area fraction fields

Figure 10 shows the change in the ocean surface temperature (OST) before and after the initial field assimilation after 11 month of integration in the region of the Barents Sea and the Kara Sea in Russia. It is seen that in general, there is a rise in temperature (the difference between the corresponding temperatures is negative); however, in the northern zone of the Barents Sea, we can see a local decrease in temperature, apparently related to the reduction of the warm water inflow from the Atlantic Ocean. This result corresponds to different independent investigations, for example, [24]. 
Разность температуры поверхности океана до и после усвоения через 11 мес. интегрнрования


Fig. 10. Difference between the surface temperature fields after 11 months of integration starting from the initial control field without data assimilation and from the initial field with data assimilation.

Figure 11 demonstrates the change in the meridional current velocity before and after assimilation after 11 months of integration in this region of the Russian Arctic. One can remark a moderate increase of about $10 \mathrm{~cm} / \mathrm{s}$ in the flow velocity; however, in the region of Novaya Zemplya, the velocities, on the contrary, decrease.

Разность меридиональной компоненты теченнй до и после усвоения через 11 мес. интегрировання

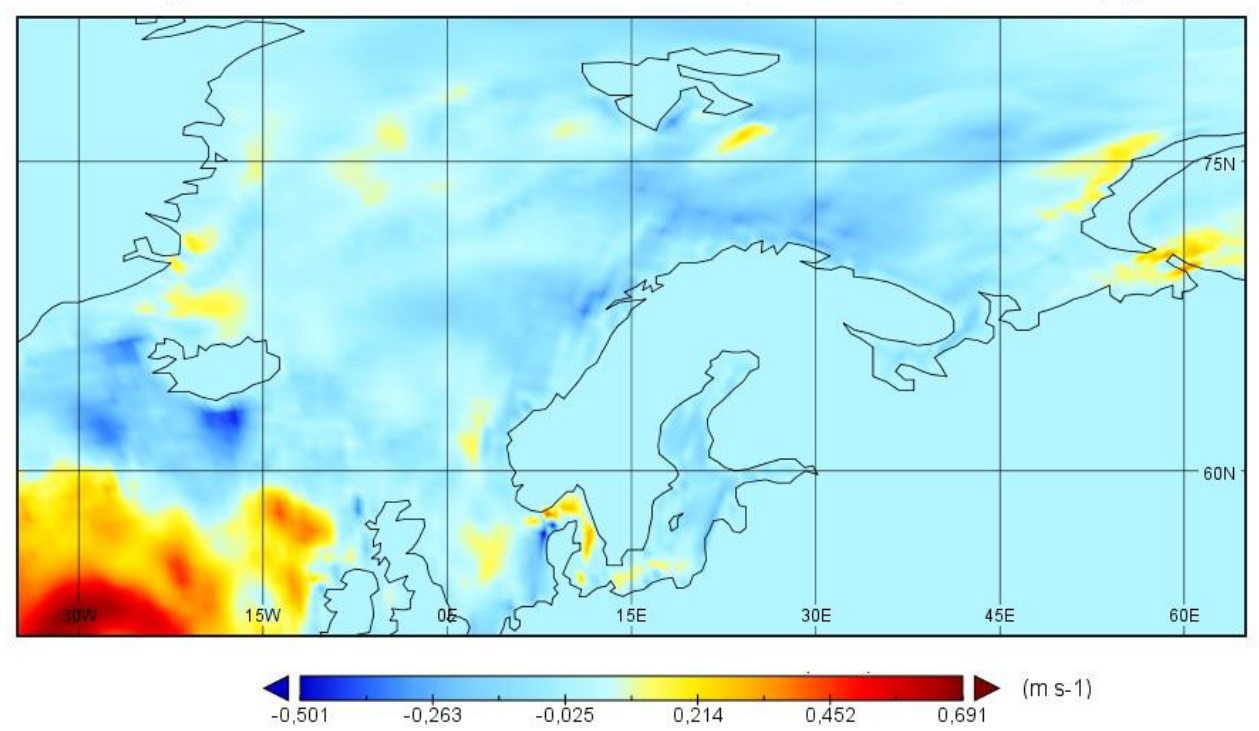

Fig. 11. Difference between the meridional velocity fields after 11 month of integration starting from the initial control field without data assimilation and from the initial field with data assimilation.

On the whole, the water dynamics in the Russian zone of the Arctic is a consequence of global tendencies in the World Ocean. 


\section{CONCLUSIONS}

The numerical experiments performed in our study allow us to come to conclusion that the model climatic fields after assimilation of the observed data considerably change not only the measured and assimilated quantities, in particular, temperature and salinity, but also the quantities that are not directly measured and are derived from the balance equations, in particular, the velocities of currents. Using visualization facilities, it is shown that the application of data assimilation methods significantly corrects qualitatively and quantitatively the characteristics of the model physical quantities, namely, the heat and mass transport. The corrections obtained as a result of application of the data assimilation method can be significant and their values can reach $100 \%$ of the values of the model calculations with no data assimilation.

The changes in the calculation parameters obtained in the integration with the control and assimilated initial fields have a global character and agree with the observed data and natural tendencies.

The calculated characteristics of the heat and mass flows are in agreement with known estimates; at that, they are more detailed.

\section{REFERENCES}

1. Tropical Oceans Global Atmosphere (TOGA) archive. URL:http://isccp.giss.nasa.gov/projects/togacoare.html

2. Pilot Research Array in the Tropical Atlantic (PIRATA) archive. URL: http://www.pmel.noaa.gov

3. Argo drifter data. URL: http://www.argo.ucsd.edu

4. World Ocean Circulation Experiment (WOCE). URL: https://www.nodc.noaa.gov/woce/

5. Jungclaus J.H., Fischer N., Haak H., Lohmann K., Marotzke J., Matei D., Mikolajewicz U., Notz D., Storch J.S. Characteristics of the ocean simulations in the Max Planck Institute Ocean Model (MPIOM) the ocean component of the MPI-Earth system model. JAMES. 2013. No. 2. P. 422-446.

6. Volodin E.M., Mortikov E.V., Kostrykin S.V., Galin V.Y., Lykosov V.N., Gritsun A.S., Diansky N.A., Gusev A.V., Yakovlev N.G. simulation of modern climate with the new version of the INM RAS Climate model 2012 // Izvestiya, Atmospheric and Ocean Physics. 2017. V. 53. No. 2. P. 142-155.

7. Belyaev K.P., Tanajura C.A.S., Tuchkova N.P. Comparison of methods for ARGO drifters data assimilation into a hydrodynamical model of the Ocean // Oceanology. 2012. V. 52. No. 5. P. 593-603.

8. Kalnay E. et al. The NCEP/NCAR 40-years reanalysis project // Bulletin AMS. 1996. V. 77. No. 3. P. 437-471.

9. Belyaev K.P., Kirchner I., Kuleshov A.A., Tuchkova N.P. Numerical realization of hybrid data assimilation algorithm in ensemble experiments with the MPIESM coupled model. In: Velarde M., Tarakanov R., Marchenko A. (eds) The Ocean in Motion. Springer Oceanography. Springer, Cham. 2018. P. 447-459.

10. Marchuk G.I., Sarkisyan A.S. Mathematical modeling of circulation in the Ocean. Moscow, Nauka. 1988. (in Russian)

11. Zalesny V.B., Rusakov A.S. Numerical algorithm of data assimilation based on splitting and adjoint equation methods // Russ. J. Numer. Anal. Math. Modelling. 2007. V. 22. No. 2. P. 199-219.

12. Evensen G. Data Assimilation, The Ensemble Kalman Filter. 2nd ed. Berlin: Springer. 2009. $307 \mathrm{p}$.

13. Korotaev G.K., Knysh V.V., Lishaev P.N., Sarkisyan A.S. Reanalysis of seasonal and interannual variability of Black Sea fields for 1993-2012 // Izvestiya, Atmospheric and Ocean Physics. 2016. V. 52. No. 4. P. 418-430. 
14. Kaurkin M.N., Ibrayev R.A., Belyaev K.P. ARGO data assimilation into the ocean dynamics model with high spatial resolution using Ensemble Optimal Interpolation (EnOI) // Oceanology. 2016. V. 56. No 6. P. 774-781.

15. Belyaev K., Kuleshov A., Tanajura C.A.S., Tuchkova N. An optimal data assimilation method and its application to the numerical simulation of the ocean dynamics // Mathematical and Computer Modelling of Dynamical Systems. 2018. V. 52. No. 1. P. 15-25.

16. Belyaev K.P., Kuleshov A.A., Tanajura C.A.S., Tuchkova N.P. A correction method for dynamic model circulations using observational data and its application in Oceanography // Mathematical Models and Computer Simulations. 2016. V. 8. No. 4. P. 391-400.

17. Morozov E., Demidov A., Tarakanov R., Zenk W. Abyssal Channels in the Atlantic Ocean: Water Structure and Flows. Springer. 2010. 266 p.

18. Antonov J.I., Seidov D., Boyer T.P., Locarnini R.A., Mishonov A.V., Garcia H.E., Baranova O.K., Zweng M.M., Johnson D.R. World Ocean Atlas. V.1: Temperature. 2009. V. 2: Salinity. 2010. Ed. S. Levitus. NOAA Atlas NESDIS 69. U.S. Gov. Print. Off., Washington, D.C.

19. Kalnay E. et al. NCEP-NCAR 40-Year Reanalysis Project paper 1. Bulletin of AMS. 1996. V. 77. No. 3. P. 437-462.

20. The international thermodynamic equation of seawater: Manual and Guide. UNESCO. 2010. No. 56.

21. Rhein M., Stramma L., Krahmann G. The spreading of Antarctic bottom water in the tropical Atlantic. Deep Sea Res. I. 1998. V. 45. P. 507-527.

22. Numerical Modeling in the Global Atmosphere in the Climate System. NATO Science Series. Ser. C. Mathematical and Physical Sciences V. 550. Eds Ph. Note, A. O'Neill. Kluwer Acad. Publisher. 1998. 498 p.

23. Belyaev K.P., Tuchkova N.P., Cubash U. Response of a coupled ocean-ice-atmosphere model to data assimilation in the Tropical Zone of the Pacific Ocean // Oceanology. 2010. V. 50. No. 3. P. 306-316.

24. Matishov G.G., Denisov V.V., Zhichkin A.P., Moiseev D.V., Gromov M.S. Modern climatic tendencies in the Barents Sea // Doklady Earth Sciences. 2011. V. 441. No. 1. P. 16021606. 